\title{
O ensino de um gênero textual oral e a elaboração de uma ferramenta didática
}

\author{
The teaching of an oral textual genre and the elaboration of \\ a didactic tool
}

\section{La enseñanza de un género textual oral y la elaboración de una herramienta didáctica}

\author{
Luzia Bueno $^{1}$ \\ Juliana Bacan Zani²
}

\begin{abstract}
RESUMO: Este artigo tem por objetivo apresentar uma pesquisa de doutorado cuja finalidade foi elaborar uma ferramenta didática para o ensino do gênero comunicação oral em eventos científicos, compreendendo o seu trabalho e as implicações deste para o desenvolvimento de capacidades de linguagem dos alunos, contribuindo, desta forma, para o letramento acadêmico desses discentes. Os aportes teóricos que orientaram esse trabalho apoiam-se na perspectiva teórico metodológica do interacionismo sociodiscursivo (BRONCKART, 2006, 2008a, 2008b, 2009, 2013; SCHNEUWLY; DOLZ, 2004; MACHADO; ABREU-TARDELLI; CRISTOVÃO, 2009), nos estudos de didáticas das línguas (SCHNEUWLY; DOLZ, 2004), na metodologia da engenharia didática (DOLZ, 2016) e nos conceitos de gestos didáticos (SCHNEUWLY; DOLZ, 2009). Os resultados obtidos, de um ponto de vista macro, ajudaram, especialmente, apreender o funcionamento da sequência de ensino, analisada, assim, pela perspectiva do objeto de ensino e dos objetos efetivamente ensinados, revelando particularidades implícitas às práticas do professor. Nesse processo, a pesquisa se constituiu, de maneira dialética, validando a importância de o sistema didático de ensino estar sustentado no professor, aluno e no objeto do conhecimento, no caso desta pesquisa, o gênero "a comunicação oral em eventos científicos".
\end{abstract}

PALAVRAS-CHAVE: Gêneros textuais. Comunicação oral. Capacidades de linguagem. Sequência didática. Gestos didáticos.

ABSTRACT: This article aims to present a doctoral research whose purpose was to elaborate a didactic tool to the teaching of the oral communication genre in scientific events, comprehending its work and its implications to the development of student's

\footnotetext{
${ }^{1}$ Professora Dr. a do Programa de Pós-Graduação Stricto Sensu em Educação pela Universidade São Francisco - Itatiba-SP. - luzia_bueno@uol.com.br

2 Doutora em Educação pela Universidade São Francisco - Itatiba-SP. zani.julianabacan@gmail.com
} 
language capacities, contributing, in this way, to the academic literacy of these students. The theoretical contributions that guided this paper base themselves on the theoretical methodological perspective of the sociodiscursive interactionism (BRONCKART, 2006, 2008a, 2008b, 2009, 2013; MACHADO; ABREU-TARDELLI; CRISTOVÃO, 2009; SCHNEUWLY; DOLZ, 2004), in the didactic engineering methodology (DOLZ, 2016), and in the concepts of didactical gestures (SCHNEUWLY; DOLZ, 2009). The results obtained, from a macro point of view, helped, specially, to apprehend the functioning of the teaching sequence, thus analyzed by the perspective of the objects of teaching and the objects effectively taught, reveling implicit particularities to the teacher's practice. In this process, the research was constituted, in a dialectical way, validating the importance of the didactic teaching system being sustained in the teacher, student and object of knowledge, in this research's case, the "oral communication in scientific events" genre.

KEY WORDS: Textual genre. Oral communication. Language capacities. Didactical sequences. Didactical gestures.

RESUMEN: Este artículo tiene como objetivo presentar una investigación de doctorado, cuya finalidad fue elaborar una herramienta didáctica para la enseñanza del género comunicación oral en eventos científicos, comprendiendo su trabajo y las implicaciones de este para el desarrollo de capacidades de lenguaje de los alumnos, contribuyendo de esta forma, para la capacitación académica de esos alumnos. Los aportes teóricos que orientaron este trabajo se apoyan en la perspectiva teórico metodológica del interaccionismo socio discursivo (BRONCKART, 1999/2009, 2006, 2008, 2013; SCHNEUWLY y DOLZ, 2004; MACHADO, 2009), en los estudios de didácticas de las lenguas (SCHNEUWLY y DOLZ, 2004/2013), en la metodología de la ingeniería didáctica (DOLZ, 2009, 2016) y en los conceptos de gestos didácticos (SCHNEUWLY; DOLZ, 2009). Los resultados obtenidos desde un punto de vista macro, ayudaron especialmente a aprehender el funcionamiento de la secuencia de la enseñanza, analizada por la perspectiva del objeto de la enseñanza y de los objetos efectivamente enseñados, revelando particularidades implícitas en las prácticas del profesor. En ese proceso la investigación se constituyó de forma dialéctica, validando la importancia de que el sistema didáctico es sostenido por el profesor, el alumno y por el objeto de conocimiento, en el caso de esta investigación, el género "la comunicación oral en eventos científicos".

Palabras-clave: Géneros textuales. Comunicación oral. Capacidades de lenguaje. Ssecuencia didáctica, gestos didácticos.

\section{Introdução}

Construir novos saberes sobre o ensino e a aprendizagem da comunicação oral acadêmica é o caminho deste trabalho, que consideramos importante para as pesquisas científicas. $\mathrm{O}$ olhar analítico que se coloca no processo de ensino e aprendizagem é um fator fundamental para identificar as dimensões do gênero efetivamente ensinado e compreendermos os obstáculos de aprendizagem, os 
dispositivos e as ações docentes, que, interligados, podem transformar um objeto de ensino em um objeto ensinado.

Para discutir esta temática, partimos de uma pesquisa de doutorado, já finalizada, cujo objetivo foi elaborar uma ferramenta didática para o ensino do gênero comunicação oral em eventos científicos, compreendendo o seu trabalho e as implicações deste para o desenvolvimento de capacidades de linguagem dos alunos, contribuindo, desta forma, para o letramento acadêmico desses discentes.

A fim de apresentarmos reflexões decorrentes desta pesquisa, organizamos este artigo em cinco seções. Primeiramente, apresentamos o conceito de didática das línguas e engenharia didática. $\mathrm{Na}$ segunda, consideramos nossa postura epistemológica e os propósitos de nosso estudo. $\mathrm{Na}$ terceira seção, abordamos os resultados obtidos na análise das sequências didáticas. Em seguida, na quarta seção, discutimos a validação do dispositivo didático criado para a comunicação oral em eventos científicos. Por fim, na última seção, expomos nossas considerações.

\section{A didática das línguas}

Ao longo dos anos, os trabalhos em didática das línguas envolveram pesquisas para observar e compreender o desenvolvimento da linguagem nas aulas, tanto teórico quanto prático, não se limitando a abordar apenas o que e como ensinar.

A didática das línguas se interessa em investigar o que se passa entre o professor e os alunos e quais são os saberes mobilizados, tanto os ensinados pelo docente, quanto a apropriação desses saberes pelos discentes. Essa tríade corresponde ao triângulo didático, ligado a um determinado contexto e dividido em três campos: meio educacional, meio científico e meio social, que "estão em interação e exercem uma influência convergente ou divergente ao funcionamento deste triângulo didático" (DOLZ, 2016, p. 240). 
Em síntese, baseado nas figuras de triângulo didático e contexto pluridimensional do triângulo didático, expostos por Silva (2013), elaboramos uma nova figura que integra o sistema didático (professor, aluno e objeto de ensino) dentro de um contexto sócio-histórico mais amplo.

Figura 1 - Triângulo didático e o contexto pluridimensional

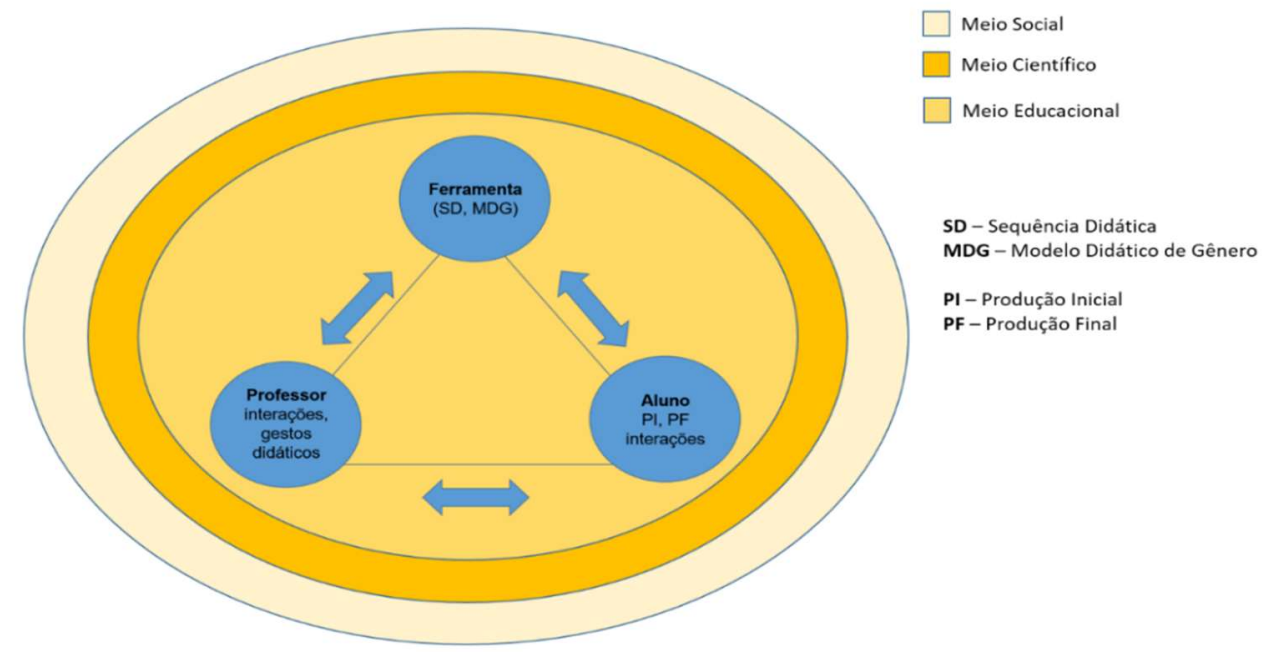

Fonte: Zani (2018).

Assim, é nessa relação entre os três polos do triângulo didático, observados dentro de um contexto mais amplo, que as pesquisas na área da didática das línguas se realizam. Esse contexto é dividido em três zonas, sendo: a primeira, o meio educacional, zona mais próxima do sistema educativo; a segunda, o meio científico, no qual os saberes disciplinares são elaborados e a terceira, o meio social, que é o mais englobante e que tem uma influência nas escolhas dos objetos de ensino e aprendizagem.

Portanto, no ensino de uma língua (primeira ou segunda), é preciso considerar os objetos a serem ensinados e como são constituídos, quais são os estatutos da língua a ser ensinada, em que níveis os alunos se encontram, quais são as metodologias e ferramentas utilizadas para o ensino e os resultados de todo o processo, ou seja, a avaliação.

Para Dolz et al. (2009, p. 36), no contexto da didática das línguas, o ensino deve "levar em consideração os conhecimentos prévios dos alunos, seu nível de desenvolvimento de linguagem" e também "dar acesso aos modelos linguageiros mais reconhecidos socialmente". 
Nesta vertente, a didática das línguas caminha entre os domínios da educação e da linguagem, situada no cruzamento de dois grandes campos do conhecimento. "No domínio do ensino e da aprendizagem, ela se situa entre a ciência da educação e a psicologia; no domínio da linguagem situa-se, particularmente, entre a linguística e a teoria literária" (DOLZ, 2016, p. 240).

Logo, a didática das línguas se caracteriza por dois tipos de pesquisa: aquelas de engenharia didática, consistentes em elaborar e avaliar novos métodos e materiais de ensino e as pesquisas fundamentais consistentes na análise das práticas de ensino na aula para compreender como se ensina e aprende.

A expressão engenharia didática emerge na didática francesa da matemática nos anos 80 , e procurava estabelecer uma metodologia de pesquisa que permite conciliar a produção de conhecimentos com as ações no ambiente escolar, buscando uma legitimidade científica.

De acordo com Brousseau (2013, p. 11), a engenharia didática tinha a preocupação em criar modelos significativos e pertinentes aos dispositivos de ensino de um conhecimento preciso, destinado a descrever ou explicar os eventos observáveis de um episódio de ensino.

Ao longo dos anos, a engenharia didática foi sendo discutida e ganhando novos rumos. Atualmente, a engenharia didática não é mais certamente, uma didática dentro do âmbito da matemática. Na didática do Francês, após os anos 80, encontramos os trabalhos de Schneuwly e Dolz (2009) que constatam diferenças importantes entre os componentes das sequências de ensino obtidos nas pesquisas e sua implementação efetiva nas classes observadas. Assim, a engenharia didática pode ser considerada como uma metodologia a qual permite analisar a diversidade de implementação de um trabalho invariante.

Garcia-Debanc (2009) destaca que a engenharia didática se torna uma metodologia, permitindo analisar os modelos disciplinares em atos de ensino e as resistências às modificações das práticas de ensino, acompanhando as mudanças. Sendo assim, uma engenharia didática é, simultaneamente, 
resultante de pesquisas em didática e uma metodologia de produção de novos conhecimentos.

Portanto, a engenheira didática "tem a responsabilidade de conceber projetos escolares e de elaborar dispositivos, atividades, exercícios, materiais escolares e novas tecnologias da comunicação escrita, oral e audiovisual' (DOLZ, 2016, p. 241).

De acordo com Dolz (2016), a engenharia didática possui quatro fases, sendo: 1) análise prévia do objeto de ensino - fase de conhecer o objeto de ensino, do ponto de vista linguístico e epistemológico; 2) concepção do protótipo de um dispositivo didático - etapa de elaboração de uma ferramenta para trabalhar com diferentes atividades centradas nos obstáculos encontrados pelos alunos; 3) implementação do dispositivo - fase de experimentação para ajustar as atividades, seja nos obstáculos encontrados pelos alunos ou nas dificuldades do trabalho do professor; 4) avaliação dos resultados observados - esta última fase refere-se a analisar os resultados obtidos com a implementação do dispositivo, destacando as vantagens e os limites do dispositivo criado.

Nesse sentido, a engenharia didática estabelece uma relação direta com as pesquisas sobre o trabalho do professor, pois as ações docentes correspondem às suas motivações escolares, ora do ponto de vista do agir docente, na realização de diferentes situações, ora do agir didático, em suas condições específicas de atuação em sala de aula, que podem ser analisadas em gestos didáticos.

Nos estudos sobre os objetos ensinados, Schneuwly e Dolz (2009) postulam que os gestos didáticos estão ligados aos objetos de ensino e a sua construção, pois, em cada situação de aula, o professor mobiliza diferentes gestos imbricados no objeto ensinado.

Os gestos, estudados do ponto de vista da didática,

[...] são portadores de significados, cujo objetivo é transformar os significados atribuídos pelos alunos aos objetos e construir, gradualmente, novas significações compartilhadas pela classe, o mais próximo possível dos significados sociais de referência. (SCHNEUWLY, 2009, p. 36, tradução nossa). 
A priori, os gestos didáticos fundadores foram propostos para identificar e conceituar dois gestos que fundam o sistema de atuação do professor: o de presentificação e o de focalização ou elementarização. 0 gesto didático de presentificação consiste em apresentar aos alunos, por meio de ferramentas/dispositivos adequados, os objetos de ensino a serem apreendidos. E o gesto de focalização consiste em delimitar e evidenciar as dimensões ensináveis do objeto, ou seja, o conteúdo propriamente dito.

As transformações dos objetos de ensino na aula são reguladas por quatro gestos didáticos fundamentais: 1) implementação dos dispositivos didáticos forma ou intervenções didáticas que o professor realiza para a apresentação do objeto de ensino; 2 ) regulação das aprendizagens - intervenções dos professores na superação dos obstáculos encontrados durante o processo de aprendizagem dos alunos. A regulação baseia-se em regulação interna (obtenção de informações sobre o estado de conhecimento dos alunos) e regulação local (interações do professor com os alunos operando no interior das atividades escolares). (SCHNEUWLY, 2009, p. 38); 3) institucionalização - fixação de conhecimentos já construídos sócio-historicamente na ação de ensino de um determinado objeto e; 4) criação de memória didática - construção de um conhecimento comum a ser compartilhado pela sala, dando um sentido de totalidade ao objeto, situando o que já foi, o que está sendo e o que será ensinado.

\section{Paradigmas epistemológicos}

Partindo de um contexto acadêmico e considerando que as práticas de letramento na educação superior têm sido foco de pesquisa de diferentes estudiosos da linguagem (CAVALARO, 2019; LOUSADA; DEZUTER, 2016; MORETTO, 2014; SOUZA; SITO, 2010; ZAVALA, 2010), em nossa pesquisa de doutorado nos centramos em buscar ferramentas para o ensino de gêneros orais e contribuir para o desenvolvimento das capacidades de linguagem ligadas à 
comunicação oral em eventos científicos, para estudantes de pós-graduação stricto sensu (mestrado e doutorado).

A comunicação oral em eventos científicos é um dos gêneros textuais que pertence à esfera da carreira acadêmica, sendo uma ferramenta para o pesquisador divulgar, em um determinado tempo - 20 a 30 minutos, mais ou menos, sua pesquisa em curso ou concluída, permitindo, posteriormente, que os dados apresentados sejam discutidos.

Assim, em nossa pesquisa de doutorado, tomamos o gênero textual "a comunicação oral em eventos científicos" como uma ferramenta potencial para o desenvolvimento das capacidades de linguagem dos alunos de programas de pós-graduação stricto sensu, promovendo as capacidades essenciais para a apropriação de uma prática linguageira acadêmica e científica e não apenas como reprodutores de um gênero de texto que circula nesta esfera.

Desenvolver as capacidades de linguagem constitui-se em dar condições ao aluno de agir com a linguagem em diferentes práticas sociais. Schneuwly e Dolz (2004) afirmam que as noções de capacidades de linguagem evocam os conhecimentos de um aprendiz para a produção de um gênero. Isto é, em uma situação de interação determinada, o aprendiz precisa, assim, "adaptar-se às características do contexto e do referente (capacidade de ação); mobilizar modelos discursivos (capacidades discursivas); dominar as operações psicolinguísticas e as unidades linguísticas (capacidades linguístico-discursivas) (SCHNEUWLY; DOLZ, 2004, p. 52). Nas situações de emprego de gêneros orais, podemos acrescentar ainda a capacidade não-linguística que, articulada às anteriores, diz respeito à voz, postura física, controle dos gestos, maior ou menos aproximação do público, entre outras características relevantes em uma situação de comunicação oral, conforme Schneuwly e Dolz (2004).

Essas capacidades de linguagem funcionam de forma articulada e interligada, contribuindo, assim, para a apropriação de um gênero textual escrito ou oral de forma global. A análise e a observação dessas capacidades, antes e durante o processo de ensino, permitem a realização de uma intervenção didática 
mais precisa por parte do professor, a fim de mobilizar os conhecimentos que os aprendizes ainda não tenham e que possam ir adquirindo durante o processo.

Para analisar textos pertencentes a um determinado gênero de texto, no nosso caso "a comunicação oral em eventos científicos", baseamo-nos no quadro teórico metodológico do Interacionismo Sociodiscursivo (ISD) de Bronckart (2006, 2008a, 2008b, 2009), que traz o modelo de análise de textos (a situação de produção, a infraestrutura textual (plano geral do conteúdo temático, tipos de discursos e tipos de sequência), os mecanismos de textualização (dentro dos mecanismos de textualização, analisamos também os marcadores conversacionais) e os mecanismos enunciativos; além dos aspectos nãolinguísticos.

Partindo desse quadro, o nosso interesse centrou-se em três etapas: conhecer melhor o gênero e suas possíveis dimensões a serem ensinadas; quais são as necessidades e potencialidades de aprendizagem dos alunos e; como determinar as estratégias de ensino a uma situação particular.

Iniciamos pela caracterização do gênero "a comunicação oral em eventos científicos" e os seus usos, de maneira a poder estudar a forma de transpor para a formação dos estudantes de pós-graduação stricto sensu (mestrado e doutorado). Sendo assim, primeiramente, entendemos o Modelo Didático de Gênero - MDG e a Sequência Didática - SD como uma metodologia de ensino, que necessita de bases teóricas para sustentá-la.

O MDG é construído após o levantamento das características dos textos pertencentes a um determinado gênero, e considerado como sendo a descrição das características ensináveis deste, o MDG é, portanto, uma das etapas importantes e necessárias para a realização da intervenção didática.

Essa intervenção é a realização de um conjunto de atividades sistematicamente organizadas, em torno de um gênero de texto (textual oral ou escrito), denominado como sequência didática - SD.

Nesse sentido, consideramos o MDG da "comunicação oral em eventos científicos" essencial para a elaboração de ferramentas didáticas (no nosso caso a sequência didática), pois possibilitará, por meio dos módulos, mobilizar as 
capacidades de linguagem dos alunos. A SD também pode ser considerada como uma ferramenta mediadora da ação do professor no processo de apropriação de um objeto de ensino. Logo, a SD pode propiciar um trabalho na zona proximal de desenvolvimento (ZPD) dos alunos, pois, por meio dos módulos, é possível criar um espaço de reestruturação entre os saberes já adquiridos e os novos sobre um objeto de ensino.

Os módulos da SD são as ferramentas do professor para criar a tensão necessária para a aprendizagem e o desenvolvimento do aluno. Mas isso implica seguir uma linha didática, explorando módulos que possibilitem trabalhar com as dificuldades dos alunos, dando ferramentas necessárias para superá-las.

Assim, é preciso conceber tecnicamente as tarefas e as ações dos alunos para aprender um objeto de ensino, coordenar as intervenções dos professores e elaborar dispositivos suscetíveis aos problemas e obstáculos detectados ao longo do processo de ensino e aprendizagem, e a engenharia didática permitirá esse processo.

Para melhor compreensão, apresentamos, a seguir, uma figura que sintetiza o percurso trilhado para o levantamento de material e coleta de dados da nossa pesquisa.

Figura 2 - Percurso da Pesquisa

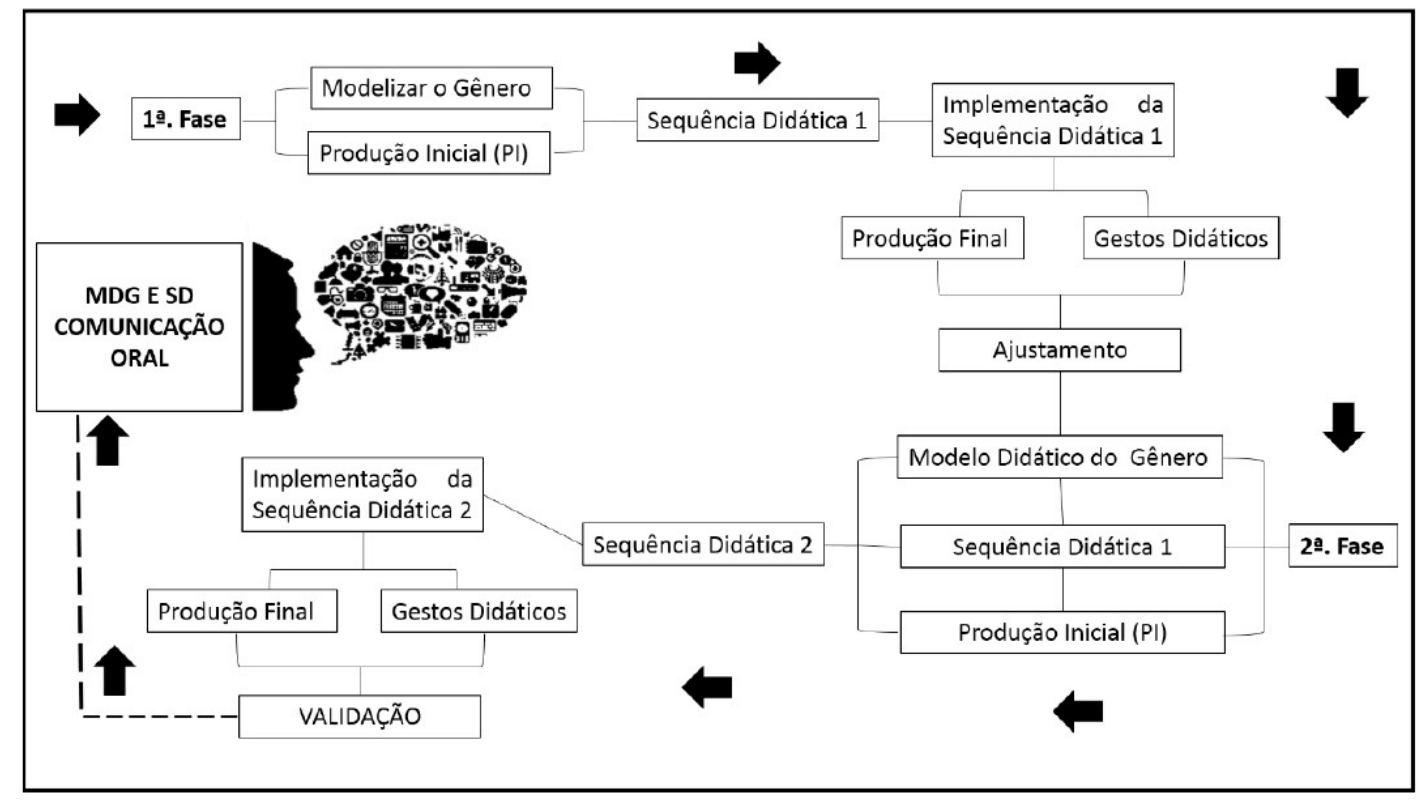


Fonte: Zani (2018).

A pesquisa partiu de um interesse de exploração em duas etapas, em dois momentos e contextos diferentes. Na fase 1 , iniciamos a análise do modelo didático da exposição oral, proposta por Schneuwly e Dolz (2004) e do modelo didático do gênero a arguição do candidato para qualificação ou defesa de mestrado e doutorado desenvolvido por nós (ZANI; BUENO, 2013). Conforme exposto anteriormente, um modelo didático é construído após o levantamento das características dos textos pertencentes ao gênero, sendo considerado como a descrição das características ensináveis deste.

Após a análise dos dois modelos didáticos, sentimos a necessidade de definir o gênero "comunicação oral em eventos científicos" e de organizar um esquema com as principais características do gênero, ou seja, modelizá-lo, se fazendo necessária para orientar a elaboração das sequências didáticas que foram utilizadas na nossa pesquisa e também servir de suporte para outras sequências em futuros trabalhos.

O protótipo da SD1 é aplicado por uma das pesquisadoras deste trabalho, direcionado a um grupo de alunos de pós-graduação stricto sensu (mestrado e doutorado) uma instituição particular de ensino ${ }^{3}$, como proposta de um minicurso sobre "A comunicação oral em eventos acadêmicos". Baseado no modelo didático do gênero comunicação oral em eventos científicos e com os resultados da análise da primeira produção dos alunos, desenvolvemos a sequência didática 1 (SD1).

As aulas do minicurso foram registradas por um minigravador digital de voz - Sony ICD-PX240. E as apresentações dos alunos foram registradas em vídeo, por uma máquina fotográfica e, simultaneamente, por um aparelho de celular, Iphone 4. Todo material gravado em áudio e vídeo (aproximadamente 18 horas e meia), produzido nesta primeira etapa, foi transcrito, em sua integralidade, pela pesquisadora. A transcrição foi feita de acordo com Preti

\footnotetext{
${ }^{3}$ Descrição completa do contexto podem ser vistos em Zani (2018).
} 
(1999, p. 11-12), Projeto de Estudo da norma linguística Urbana Culta de São Paulo (NURC-SP), núcleo USP.

Considerando a imensa quantidade de dados recolhidos, sentimos a necessidade de um procedimento sistemático para organizar os dados gerados, de maneira a reduzi-los e ao mesmo tempo guiar o nosso olhar e facilitar as análises. Assim, com o propósito de descrever os dados sem perder de vista os conteúdos e modificar seu sentido, optamos por utilizar a ferramenta metodológica "sinopse".

Esta ferramenta permite "uma descrição das principais partes, ações e principais conteúdos abordados" tornando possíveis a comparação e as análises das sequências de ensino sobre um objeto delimitado. (CORDEIRO; RONVEAUX, 2009, p. 90). Para os autores, a sinopse possibilita a compreensão da estrutura de uma sequência de ensino, sem recorrer à transcrição original.

A redução das informações para a sinopse coloca em evidência a organização sequencial e hierárquica de uma sequência de ensino, sendo que os conteúdos destacados ou descartados são determinados pelo objetivo da pesquisa. Assim, o nosso interesse para utilização desta ferramenta é triplo.

Primeiramente, ela permitirá uma percepção sintética do objeto "a comunicação oral em eventos científicos" em uma sequência de ensino, tendo uma visão do todo e de suas partes decompostas pelas atividades escolares. Em segundo lugar, permitirá destacar os conteúdos e as dimensões do objeto de ensino a serem contemplados. E por fim, permitirá uma visão geral das atividades escolares implementadas sobre o objeto de ensino e os gestos mobilizados pelo professor.

Após a análise dos resultados, o protótipo inicial é retomado, são feitos os ajustes necessários e um novo protótipo é proposto, a SD2, que é aplicada por um professor/especialista em didática do ensino e para um grupo de participantes de um simpósio internacional sobre gêneros textuais, neste caso, os alunos que

\footnotetext{
${ }^{4}$ Desenvolvida pelo grupo de pesquisa GRAFE (groupe de recherche pour l'analyse du français enseigné) da Universidade de Genebra, a sinopse se apresenta como um meio eficiente de condensar os dados de uma sequência de ensino filmada e como um analisador confortável das práticas pedagógicas.
} 
participaram do minicurso, sendo mestrandos, doutorandos, professores, pesquisadores, entre outros.

A implementação da sequência didática permitiu a exploração de novas pistas de investigação durante o processo e, por ser um protótipo e estar em fase de "teste", facilitou os ajustes necessários para a constituição de uma nova sequência didática, constituindo-se, assim, em uma engenharia didática.

Na nossa perspectiva consideraremos, simultaneamente, as capacidades orais iniciais dos estudantes, as capacidades profissionais dos formadores para compreender as interações formativas da ação didática, sendo coerente nas ações entre o professor/formador e os alunos sobre o objeto de ensino.

Partimos do pressuposto de que uma situação de ensino é um sistema que se constrói ao redor das intervenções que se direcionam e se ajustam em um determinado contexto e que também se define a partir da história de seus atores e os objetivos que estes Ihe dão. Assim, nossa pesquisa se apoia, também, na análise das práticas dos professores (gestos didáticos) que, ao colocar o objeto de ensino em evidência, permite a co-construção de um conhecimento.

Dessa forma, ampliamos as nossas análises trazendo foco para três elementos essenciais para a implementação de uma ferramenta didática: os objetos/ferramentas de ensino, o desenvolvimento das capacidades de linguagem dos alunos e o professor no seu agir didático.

\section{Resultados obtidos na análise das sequências didáticas}

Confrontando as produções iniciais dos alunos participantes das duas etapas desta pesquisa, constatamos que os alunos têm um conhecimento sobre o contexto de produção, principalmente nas discussões durante as aulas, mas na apresentação da comunicação (produção inicial) esse aspecto não fica evidente, pois a grande maioria não conseguiu se adaptar às características do contexto de produção (papel do enunciador, destinatários, tempo da apresentação) e ao conteúdo temático em que a comunicação estava inserida. Dessa forma, podemos destacar que há uma pequena mobilização nas capacidades de ação. 
Em relação às capacidades discursivas, os participantes apresentaram o título do da comunicação e uma estrutura temática, principalmente nas fases de abertura, encadeamento das diferentes partes (objetivos, fundamentação teórica, metodologias), embora não muito bem relacionados ao título da comunicação. Os tipos de discurso recorrentes foram o discurso interativo e teórico. Já nas capacidades linguístico-discursivas, os alunos apresentam um maior domínio na utilização dos diferentes marcadores, principalmente os que têm a função de garantir os pontos de articulação de uma temática a outra. Percebe-se que, entre os participantes, poucos fazem uso de marcadores de inserção explicativa ou ilustrativa e de segmentos de reformulações retóricas ou saneadoras, aspectos estes que ajudam a entender o conteúdo temático que está sendo abordado.

Nas capacidades não-linguísticas, observamos que os alunos têm consciência do uso da voz, como ritmo, velocidade e entonação, mas os aspectos relacionados à gestão do corpo (gestos, troca de olhares, expressão facial) precisam de uma atenção maior. Em relação ao uso do suporte, apresentam criatividade e estão dentro das normas padrões em relação ao layout, tamanho de letra, entre outros, mas é falho o uso das informações e a planificação da temática.

Com a análise das produções iniciais foi possível criar módulos para uma sequência didática que considerasse os conhecimentos já adquiridos pelos alunos, levando-os a apreender outras etapas necessárias para a produção de uma comunicação oral em eventos científicos.

O levantamento das dimensões ensináveis do gênero, organizado no MDG, ajudaram a direcionar o nosso olhar para propor atividades que concentrassem nos obstáculos encontrados na comunicação oral dos alunos. Defendemos aqui a importância do diagnóstico inicial para a elaboração da SD.

Dessa forma, para o desenvolvimento das capacidades de ação, foi necessária a proposição de atividades que levassem os alunos a compreender e assumir o seu papel social diante da esfera acadêmica e os objetivos da comunicação oral nos eventos científicos. 
Em relação às capacidades discursivas, foi preciso alinhar o título da apresentação aos conteúdos temáticos e sua estruturação durante a comunicação oral. Para as capacidades linguístico-discursivas, exploramos os diferentes organizadores do discurso que irão garantir a coerência e a coesão temática. Para as capacidades não-linguísticas, trabalhamos o usar o corpo como aliado aos objetivos da comunicação oral e, por fim, saber estruturar e organizar o suporte que será utilizado.

Com base na confrontação dos resultados obtidos nas produções iniciais e finais, podemos destacar que a SD1, embora tenha possibilitado avanços no desenvolvimento das capacidades dos alunos, não atingiu os objetivos que se propunha, pois limitou-se à exploração das atividades sem relacionar as reais necessidades dos alunos.

Já a SD2 possibilitou grandes avanços na mobilização das capacidades de linguagem, demonstrando ser uma ótima ferramenta para o processo de ensino e aprendizagem.

O diagnóstico inicial (produções iniciais) dos alunos, quanto o diagnóstico final (produções finais), que compõem uma sequência didática, foram de extrema importância para a reconceptualização da nossa SD1 e SD2, como para as intervenções necessárias para o processo de ensino e aprendizagem do gênero a comunicação oral em eventos científicos. A possibilidade de diagnosticar duas vezes, e em contextos diferentes, as capacidades de linguagem que os alunos já possuíam e os desenvolvimentos alcançados, permite-nos validar a sequência didática sugerida para o ensino do gênero que estamos tratando nesta pesquisa.

\section{A validação do dispositivo didático}

O procedimento metodológico adotado nesta pesquisa permitiu um acompanhamento tanto teórico como prático, possibilitando, no decorrer do processo, fazer as alterações e as adaptações necessárias para a elaboração de uma sequência didática para o nosso objeto de ensino: "a comunicação oral em eventos científicos". 
Os resultados obtidos, de um ponto de vista macro, ajudam, especialmente, a apreender o funcionamento da sequência de ensino, analisada, assim, pela perspectiva do objeto de ensino e dos objetos efetivamente ensinados, revelando particularidades implícitas às práticas do professor. Nesse processo, a pesquisa vai se constituindo, de maneira dialética, e validando a importância de o sistema didático de ensino estar sustentado no professor, aluno e no objeto do conhecimento, no nosso caso, o gênero "a comunicação oral em eventos científicos".

Na tríade objeto de ensino, professor e aluno, um conhecimento foi sendo constituído. Acreditamos que esta pesquisa tenha atingido seu propósito inicial, contribuindo para o aprimoramento das capacidades de linguagem necessárias para a produção de um gênero de texto oral e para o campo das pesquisas do letramento acadêmico.

A organização das dimensões ensináveis da comunicação oral em eventos científicos, ou seja, a sua modelização, contribui para o professor conhecer de forma mais ampla as características do gênero que serão objeto de ensino, auxiliando-o no desenvolvimento e até mesmo na elaboração de outras sequências didáticas. A partir da nossa sugestão da sequência didática, e fazendo um diagnóstico preciso na produção inicial dos alunos, o professor tem ferramentas para desenvolver um trabalho que possa proporcionar 0 desenvolvimento das capacidades de linguagem, selecionando as atividades mais adequadas para sua intervenção.

Como destacamos ao longo deste trabalho, não havendo outros problemas contextuais, a SD poderá ter sucesso se o professor souber trabalhar a partir das necessidades particulares de cada grupo e souber selecionar as atividades pertinentes para a construção do objeto de ensino.

São nos três polos de ensino que chegamos às conclusões que citaremos a seguir:

1) o objeto de ensino - os conteúdos a serem tratados sobre o gênero a comunicação oral em eventos científicos voltam-se especificamente para o contexto de produção, no qual o aluno precisa adequar sua comunicação às 
condições particulares do evento de que irá participar, ou seja, de acordo com as normas de submissão de um trabalho. É preciso também, nesta fase, assumir o papel social que se tem ao fazer uma comunicação oral e ter bem evidente o objetivo da mesma.

A planificação do tema, a gestão do tempo e da oralidade são pontos principais para a apresentação de uma comunicação oral, pois serão elas as responsáveis por garantir a clareza e o sucesso da mensagem a ser passada ao público presente. Dessa forma, as fases de uma introdução incitativa, a apresentação do roteiro que seguirá a comunicação e o fechamento foram os aspectos que mais chamaram a atenção e se fizeram necessários para organizar os módulos da sequência didática. Da mesma forma que o uso de marcadores do discurso e os marcadores de inserções explicativas ou ilustrativas e os de reformulação também possibilitou levar os alunos a identificar como os expositores utilizam os diferentes marcadores, responsáveis pela organização do gênero a comunicação oral em eventos científicos.

2) o aluno - avaliar as capacidades de linguagem que os alunos já possuem para mobilizar o gênero a comunicação oral em eventos científicos é o ponto de partida para a elaboração de uma sequência didática. Sendo assim, o diagnóstico inicial (produção inicial) dos alunos se faz necessário. Logo, olhar para cada aluno individualmente e suas reais necessidades é o que irá garantir a progressão e desenvolvimento das capacidades de cada um. Outra questão que se evidenciou nesta pesquisa é a tomada de consciência do próprio aluno sobre as suas dificuldades. Os alunos envolvidos na pesquisa são adultos que já possuem um conhecimento científico, e trabalhar com os pontos destacados nas avaliações iniciais permite-lhes entrar na comunidade da comunicação científica, sabendo levar o seu conhecimento para serem ouvidos. O diagnóstico inicial permite seguir o itinerário do aluno e preparar-se para um congresso (real) foi primordial motivação dos alunos.

3) o professor - a forma de trabalho do professor se faz relevante para os avanços alcançados pelo aluno. Tivemos que experimentar a sequência didática duas vezes, com as devidas adaptações, para compreender que as ações do 
professor foram fundamentais para o processo de ensino e aprendizagem. $\mathrm{Na}$ segunda experimentação, seguir o itinerário dos alunos, permitindo entre eles a confrontação cruzada de suas reais necessidades possibilitou compreender os pontos fortes a serem tratados para a organização de uma comunicação oral. Assim, os gestos fundamentais se fizeram presentes nas mais diversas situações, e a forma de conselho, dada pelo professor e pela pesquisadora, contribuiu mais do que desenvolver atividades escolares que pudessem superar as reais necessidades. 


\section{Considerações finais}

Do ponto de vista do triângulo de ensino, nossa pesquisa revela a real necessidade de se trabalhar com o gênero a comunicação oral em eventos científicos partindo do diagnóstico inicial e seguindo o itinerário do aluno, colocando-o em confrontação, proporcionando um trabalho de colaboração entre os pares para o desenvolvimento das capacidades de linguagem esperadas para o gênero de texto em questão.

Desse modo, evidencia-se a necessidade de se trabalhar com o ensino de um gênero textual acadêmico. Saber falar por meio de um gênero oral não nos torna apenas falantes de uma língua, torna-nos sujeitos com poderes para agir por meio da linguagem, questionando, protestando e agindo, de verdade, em uma sociedade em que somos todos, sem exceção, ouvintes, mas com pouquíssimos espaços de nos fazermos ser ouvidos. O domínio da comunicação oral não vai alterar a sociedade brasileira, mas pode mostrar aos nossos alunos que existem maneiras de se fazer ser ouvido e isso já é um primeiro passo para uma mudança.

\section{Referências}

BRONCKART, Jean Paul. A problemática das interações entre linguagem e operações cognitivas. Revista NUPEM, Campo Mourão, v. 5, n. 9, p. 19-32; jul./dez. 2013.

BRONCKART, Jean Paul. Atividade de linguagem, discurso e desenvolvimento humano. São Paulo: Mercado de Letras, 2006.

BRONCKART, Jean Paul. Atividade de linguagem, textos e discursos. por um interacionismo sociodiscursivo. Tradução de Anna Rachel Machado. 2. ed. São Paulo: Educ, 2009.

BRONCKART, Jean Paul. $O$ agir nos discursos: das concepções teóricas às concepções dos trabalhadores. São Paulo: Mercado de Letras, 2008a.

BRONCKART, Jean Paul. Sobre linguagem, ação-trabalho e formação: as contribuições da démarche ISD: entrevista com Jean-Paul Bronckart. Educação em Revista, Belo Horizonte, n. 47, p. 273-286, jun. 2008b. 
BROUSSEAU, Guy. Introduction à l'ingénierie didactique. 2013. Disponível em: http://guy-brousseau.com/wp-content/uploads/2013/12/Introduction\%C3\%A0-ling\%C3\%A9nierie-didactique3.pdf. Acesso em: 5 jun. 2017.

CAVALARO, Felipe. Uma sequência didática do gênero resumo científico a partir do ambiente virtual. 2019. Dissertação (Mestrado em Educação) - Universidade São Francisco, Itatiba, 2019.

CORDEIRO, Glaís Sales; RONVEAUX, Christophe. Recueil et traitement des données. In: SCHNEUWLY Bernard; DOLZ, Joaquim (org.). Des objets enseignés en classe de français. Le travail de l'enseignant sur la rédaction de textes argumentatifs et sur la subordonnée relative. Rennes, Bretagne, FR: Presses Universitaires de Rennes, 2009. p. 83-100.

DOLZ, Joaquim; GAGNON, Roxane; DECÂNDIO, Fabrício R. Uma disciplina emergente: a didática das línguas. In: NASCIMENTO, Elvira Lopes (org.). Gêneros textuais. da didática das línguas aos objetos de ensino. São Carlos: Editora Clara Luz, 2009. p. 19-50.

DOLZ, Joaquim. As atividades e os exercícios de língua: uma reflexão sobre a engenharia didática. DELTA: Documentação de Estudos em Linguística Teórica e Aplicada, São Paulo, SP, v. 32, n. 1, p. 237-260, 2016.

GARCIA-DEBANC, Claudine. Quand les enseignants débutants enseignent la relation $S / V$ à la fin de l'école primaire. De l'analyse des pratiques observées à la détermination d'éléments d'expertise professionnelle. In: DOLZ, Joaquim; SIMARD, Claude. Pratiques d'enseignement grammatical. Points de vue de l'enseignant et de l'élève. AIRDF, Québec: Presses de l'Université Laval, 2009. p. $99-124$.

LOUSADA, Eliane Gouveia; DEZUTTER, Olivier. La rédaction de genres universitaires: pratiques et points de vue d'étudiants universitaires au Brésil et au Québec. Le Français à L'Université, Montreal, v. 21, n. 1, p. 1-5, 2016.

MACHADO, Anna Rachel; ABREU-TARDELLI, Lilia Santos; CRISTOVÃO, Vera Lucia Lopes (org.). Linguagem e educação: o ensino e a aprendizagem de gêneros textuais. Campinas: Mercado de Letras, 2009.

MORETTO, Milena. Um modelo didático do gênero Trabalho de Conclusão de Curso e uma perspectiva de trabalho em sala de aula. 2014. Tese (Doutorado em Educação) - Universidade São Francisco, Itatiba, 2014.

PRETI, Dino. Projeto de estudo da norma linguística urbana culta de São Paulo. São Paulo: Humanitas, FFLCH/USP, 1999. (Projeto NURC/SP - Núcleo USP).

SCHNEUWLY, Bernard; DOLZ, Joaquim. Des objets enseignés en classe de français. Rennes, Bretagne, FR: Presses Universitaire de Rennes, 2009. 
SCHNEUWLY, Bernard; DOLZ, Joaquim. Gêneros orais e escritos na escola. Tradução de Roxane Rojo e Glaís Cordeiro. Campinas, SP: Mercado de Letras, 2004.

SILVA, Carla Messias. O agir didático do professor de língua portuguesa e sua reconfiguração em textos de autoconfrontação. 2013. Tese (Doutorado em Linguística Aplicada e Estudos da Linguagem) - Pontifícia Universidade Católica de São Paulo, São Paulo, 2013.

SOUZA, Ana Lucia Silva; SITO, Luanda. Letramentos e relações raciais em tempos de educação multicultural. In: VOVIO, Claudia Lemos; SITO, Luanda; GRANDE, Paula Baracat. Letramentos. Campinas: Mercado de Letras, 2010.

ZANI, Juliana Bacan. A comunicação oral em eventos científicos. uma proposta de modelização para a elaboração de sequências didáticas. 2018. Tese (Doutorado em Educação) - Universidade São Francisco, Itatiba, 2018.

ZANI, Juliana Bacan; BUENO, Luzia. O letramento na universidade e a apresentação oral do candidato para qualificação ou defesa de mestrado e doutorado. Intercâmbio: Revista do Programa de Estudos Pós-Graduados em Linguística Aplicada e Estudos da Linguagem, São Paulo, v. 31, p. 55-71, 2015.

ZAVALA, Virgínia. Quem está dizendo isso? Letramento acadêmico, identidade e poder no ensino superior. In: VOVIO, Claudia Lemos; SITO, Luanda; GRANDE, Paula Baracat. Letramentos. Campinas: Mercado de Letras, 2010. p. 71-95. 